\title{
A METÁFORA E A ORGANIZAÇÃO DO CONHECIMENTO: COMO DIALOGAM? ${ }^{1}$
}

\author{
LA METÁFORA Y LA ORGANIZACIÓN DEL \\ CONOCIMIENTO: ¿CÓMO DIALOGAN?
}

Evelyn Orrico*

\begin{abstract}
RESUMO
Introdução: A partir do pressuposto de Johnson e Lakoff (1980), de que a organização cognitiva ocorre por via metafórica, procurou-se compreender como tal organização representaria o conhecimento. Objetivo: Propor a construção de um modelo teórico de filtro de recuperação da informação, a que se denomina de metafiltro. Metodologia: Foram analisadas as produções discursivas de um grupo de pesquisa que congrega pesquisadores iniciantes e experientes, no intuito de depreender as metáforas utilizadas para representar seu objeto de pesquisa e seu campo de conhecimento. Resultados: Pela análise, percebeu-se a metáfora ontológica da área, quer dizer, aquela que norteia todas as representações do campo, a saber: Transporte é rede sistêmica. Conclusões: A identificação da metáfora ontológica e das demais metáforas de um campo do conhecimento, quando associadas às facetas propostas por Ranganathan (1967), permite conseguir maior precisão na recuperação de informações inseridas em uma enorme base de dados como a internet.
\end{abstract}

Palavras-chave: Metáfora. Organização do Conhecimento. Recuperação da Informação. Metafiltro.

\footnotetext{
${ }^{1}$ Este texto teve como base a reflexão iniciada em $A$ representação metafórica como filtro de recuperação da informação, publicado na revista on line DataGramaZero - Revista de Ciência da Informação - em 2001.

* Evelyn Orrico. Professora Associada IV - Programa de Pós-Graduação em Memória Social Universidade Federal do Estado do Rio de Janeiro (PPGMS/UNIRIO). Email: evelynorrico@unirio.br.
}

Inf. Inf., Londrina, v. 22, n. 2, p. 99 - 116, maio/ago., 2017. 


\section{INTRODUÇÃO}

A quantidade de inscrições que atualmente circulam em diferentes contextos sociais, notadamente no ciberespaço, aumenta não só os potenciais de informação, mas também os de desinformação. Como já na metade do século passado estimou Solla Price (1965), a produção acadêmica cresce exponencialmente, e por isso tem sido de difícil transferência. Menos pela facilidade de acesso, e mais por dificuldade de selecionar o que é realmente interessante. $\mathrm{O}$ que dizer, então, desse novo espaço de disseminação que é a Internet?

Pela sua organização em rede, esse meio de comunicação virtual permite um abastecimento de dados, que provoca tanto a multiplicação quanto a aceleração da quantidade de inscrições disponíveis, e, ainda, a proliferação de forma anárquica dos contatos transversais entre os homens. Para recuperar tais dados de modo mais preciso, é necessário organizar o conhecimento produzido.

Em uma tentativa de desvendar os mistérios da organização do conhecimento a primeira pergunta a se fazer é a seguinte: qual seria a melhor forma de organizar o conhecimento? Uma pergunta difícil, ambiciosa e sobretudo audaciosa, mas é ela que nos move para procurar alternativas criativas de modo a ser viável, ao organizar o conhecimento no intuito de recuperar as informações a ele atreladas, ter condições de produzir mais conhecimento.

A segunda pergunta nessa direção é: como é possível organizar o conhecimento? É difícil pensar em modo de organização se não refletimos sobre a forma cognitiva de pensar e representar o mundo. É a partir desse pressuposto que introduzimos uma reflexão sobre as metáforas.

Por fim, por que estudar metáfora? Essa pergunta, no meu entendimento, se impõe àqueles que lidam com a organização do conhecimento porque, desde a década de 80 do século XX, sabe-se, a partir da 
afirmação de Lakoff e Johnson (1980), que a cognição humana se estrutura por via metafórica. $\mathrm{E}$ o que isso significa exatamente?

A metáfora é uma figura de linguagem que transfere um termo para uma esfera de significação que não é a sua, com a finalidade de estabelecer representação do mundo por meio de analogias. Esses autores afirmaram que o ser humano organiza o conhecimento por estruturas denominadas modelos cognitivos idealizados $(\mathrm{MCl})$, cuja organização mental se faz por intermédio da construção cultural de esquemas de conhecimento do mundo. Tais esquemas são estabelecidos no ambiente sociocultural e compartilhados pelos membros desse ambiente social. Em decorrência, as categorias de organização do mundo - e que pautam a compreensão que os seres humanos têm do mundo em que vivem - são não só cognitiva, mas também socialmente construídas.

Para ilustrar, apresento o exemplo que os próprios autores utilizaram para explicar o seu modelo: a concepção de dias da semana. Para falar dos dias da semana, os autores iniciam pela representação de fim-de-semana. No ocidente, a noção de fim-de-semana é constituída tendo por base a concepção de semana de trabalho que, por sua vez, se constitui por uma sequência de cinco ciclos solares. Se os ciclos solares existem na natureza, o mesmo não se pode dizer do recorte em sete para formar um conjunto categorial (semana) e menos ainda em cinco, para constituir a sequência de dias úteis e, ainda menos, o de fim-de-semana. Essa representação categorial é socialmente construída.

Esses autores fortaleceram seu modelo cognitivo. Propuseram o conceito de Metáfora Ontológica, como sendo aquela que, no modelo cognitivo proposto, serviria para nortear as demais representações que as pessoas fazem sobre um mesmo objeto do mundo. Esse modo de representar ocorreria pela forma como a organização cognitiva se estrutura. Ela parte de extensões semânticas cujas noções conceituais estão inicialmente próximas da concretude e dirigem-se para uma maior abstração. Um dos exemplos citados pelos autores é a metáfora do "Homem é Máquina". Essa representação - o corpo como metáfora de máquina - sustentaria cognitivamente outros 
enunciados tais como, "minha cabeça não está funcionando", "falta um parafuso na cabeça dele", bem como "ele tem um parafuso a menos"; "os intestinos não estão funcionando direito", "meu coração está rateando".

Ora, admitindo-se essa compreensão de organização cognitiva como estabelecida, a decorrência, voltada para a organização do conhecimento, foi construir a hipótese de que, se a estrutura cognitiva geral é de base metafórica, a organização do conhecimento aconteceria de maneira análoga, ou seja, os pesquisadores representariam metaforicamente os campos de conhecimento a que se dedicam. A partir daí infere-se que conhecer as metáforas que representam um campo de saber permite organizar, e consequentemente filtrar, as informações sobre esse campo de modo a se obter maior precisão na recuperação de informações sobre ele.

Assim, começou-se a formular a proposta de utilizar esse modelo representacional do mundo para aplicá-lo à representação de um campo de saber. No início dos anos 2000, quando essa proposta foi concebida (ORRICO, 2001), procurei identificar como essa representação ocorria, utilizando como campo empírico de análise a identificação de enunciados que representavam o objeto de estudo de um grupo de pesquisa sobre transportes em suas manifestações discursivas.

Naquela ocasião, pretendíamos, por meio do conhecimento das representações metafóricas sobre uma área de trabalho, propor um modelo teórico de filtro que ajudasse os membros de determinado grupo social a recuperar as informações com mais precisão. A ideia era trabalhar com as marcas linguísticas escritas que expressassem a metáfora, por intermédio de enunciados que estabelecessem a relação entre um elemento do mundo e outro.

Mais recentemente, encontrei no texto de Hartel e Savolainen (2016) uma proposta de estudo visual e artístico, que utiliza a teoria da metáfora cognitiva para explorar a natureza da informação, permitindo uma nova perspectiva a esse conceito, fortalecendo a compreensão da informação em um sentido da história, humanidade, natureza e beleza. É uma fortíssima e 
desafiadora ampliação do uso da metáfora para compreender o mundo. $\mathrm{Na}$ medida em que nas imagens não existem expressões como " $X$ é $Y$ ", ou ainda que "X se parece com $Y$ ", a imagem convida, fraca ou fortemente, o interlocutor a construir a metáfora.

No entanto, ao focar nossa investigação nas informações textuais, a sólida proposta de Ranganathan (1967) para a organização do conhecimento haveria de também ser considerada. Sua visão classificatória, embora inovadora e de repercussões importantes para a teoria da classificação como um todo, refletia a concepção moderna de construção do conhecimento, no final do século XIX e no início do século XX, que pressupunha uma delimitação precisa da área de conhecimento em que tais conceitos estivessem inseridos. Lidava-se naquela ocasião com disciplinas de limites bem demarcados, compostas de arsenal teórico conceitualmente delimitado.

Essa situação já se configurava diferentemente no início do século XXI. As disciplinas não apresentavam limites claros. Daí surgiu a proposta de unir os princípios norteadores propostos por Ranganathan com as metáforas identificadas nos enunciados produzidos pelo grupo de pesquisadores analisados para formular a proposta de metafiltro de recuperação da informação. Por que propor um metafiltro? Porque o objetivo era conceber um modelo teórico que pudesse ser utilizado posteriormente em outros e distintos objetos de estudo e campos do conhecimento.

\section{COMO PROVAR A HIPÓTESE?}

O quadro no qual uma proposta de metafiltro de recuperação da informação na Internet se inseriu no início dos anos 2000 objetivava dar conta de, pelo menos, uma situação problemática: tornar mais eficaz a recuperação da informação on-line.

O arcabouço teórico-metodológico proposto teve o intuito de permitir que um determinado grupo social recuperasse as informações que mais diretamente the interessavam, e para isso baseou-se na Semântica, mais 
especialmente nas metáforas que os grupos sociais utilizam para representar não só a área de conhecimento em que trabalham mas também os conceitos a ela ligados.

Inicialmente, era preciso delimitar uma área de conhecimento como condição fundamental para a depreensão do conjunto metafórico que o grupo dessa área utiliza para representar o seu próprio campo de trabalho e pesquisa. Optamos por um estudo de caso que desse subsídios para a elaboração da proposta de metafiltro e assim recorremos a uma equipe de pesquisa consolidada no Brasil.

Nosso campo empírico era constituído por um grupo de pesquisadores reconhecidos por seus pares em seu campo de ação e que congregava uma quantidade expressiva de pesquisadores com características fundamentais, a seguir definidas, de modo que tais atores correspondessem a uma caixa de ressonância em relação à área de conhecimento. Assim, no intuito de depreender a recorrência e a abrangência das metáforas utilizadas, foi escolhido um grupo que se constituía por membros com diferentes níveis tanto de experiência na área quanto de pertencimento ao grupo e apresentava as seguintes características:

provenientes de diferentes Estados brasileiros - característica que pode indicar o uso generalizado e recorrente das mesmas metáforas

> vinculados a diferentes Instituições de Ensino - característica que pode indicar que o jargão utilizado não se restringiria a um grupo específico

e com diferentes níveis de experiência em pesquisa - característica que pode indicar, sobretudo, que o uso das metáforas seria amplamente difundido.

A equipe de pesquisadores que atendeu a esses critérios foi a Rede de Estudos de Engenharia e Socioeconômicos de Transportes - RESET-, que vem sendo construída desde 1994 por professores e pesquisadores brasileiros vinculados a universidades públicas e a centros de pesquisa em transportes, com diferentes tempos e graus de titulação: desde obtenção de título de doutor há mais de 30 anos, até estudantes de Iniciação científica. É coordenada por 
professor que faz parte do corpo docente da Coordenação dos Programas de Pós-Graduação em Engenharia - COPPE/UFRJ -, cuja titulação de doutorado foi obtida em fevereiro de 1987 no Institut d'Urbanisme de Paris, Université Paris XII.

O corpo de pesquisadores divide-se em três níveis que espelham o nível de vinculação à própria rede, evidenciado pela regularidade e constância no envolvimento e na participação de projetos de pesquisa. Os membros da rede são assim classificados:

- pesquisadores permanentes

- pesquisadores colaboradores

- pesquisadores em formação

O instrumento de coleta de dados utilizado, para servir à metodologia de Análise de Caso, foi um questionário aplicado por correio eletrônico, que obteve um alto índice de respostas: $75 \%$ dos membros da equipe responderam. A elaboração desse questionário foi norteada por três orientações, das quais somente a última relaciona-se ao objeto deste artigo:

- Haveria maior ou menor sucesso de busca de informações na Web dependendo do nível de experiência em pesquisa do pesquisador?

- Existem traços de estratégias de busca e características comuns a esta área de conhecimento?

- Seria possível caracterizar determinadas metáforas como sendo as representativas da área?

Assim, o questionário subdividiu-se em duas partes:

A primeira parte do questionário objetivava, marcadamente já na primeira pergunta, traçar um perfil do conjunto de profissionais que compõem a rede de pesquisa; e a segunda parte do questionário tinha o objetivo de responder às duas perguntas seguintes que se relacionavam a levantar as 
estratégias de busca, para identificar as estratégias de otimização e depreender as metáforas utilizadas para representar a área.

Interessa aqui pontuar a última pergunta dessa segunda parte, porque objetivou levantar as representações utilizadas para definir a área de pesquisa em que o grupo de pesquisadores atua, no intuito de esquadrinhar as referências metafóricas utilizadas pelos pesquisadores da área.

A análise das resposta mostrou que a quase totalidade dos pesquisadores explicita o termo transportes para identificar seu assunto específico de pesquisa, só havendo duas respostas diferentes em que os termos utilizados foram rodovia e mobilidade, que pertencem à constelação conceitual do tema central. No entanto, para descrever seus respectivos temas de pesquisas, os membros do grupo utilizam uma gama extremamente variada de enfoques: histórico, estrutural, econômico, político, o que percebemos como possibilidade de um leque também abrangente de representações metafóricas que funciona como atributo do domínio Transporte.

Por fim, a pergunta que permite aproximar o conceito que melhor representaria a área de conhecimento, no intuito de depreender a grade metafórica relacionada à área de conhecimento estudada, era a seguinte: $\mathrm{O}$ que representa Transportes para você? Essa pergunta permitiria a verbalização da seguinte formulação de enunciado: Transporte é...; Transporte se parece com..., conforme apontamos acima.

Alguns pesquisadores tiveram dificuldade em responder a essa pergunta, o que corrobora a afirmação de Lakoff \& Johnson (1980, p. 3), relativa a não estarmos habitualmente atentos ao nosso sistema conceitual, como se pode ver a seguir:

Os conceitos que governam nosso pensamento não são somente matérias do intelecto. Eles também governam nosso funcionamento diário, até os detalhes mais mundanos. Nossos conceitos estruturam o que percebemos, como circulamos pelo mundo e como a gente se relaciona com outras pessoas. Nosso sistema conceitual então desempenha um papel central na definição de nossas realidades quotidianas. Se nós estivermos certos quando sugerimos que o nosso sistema conceitual é grandemente metafórico, então a maneira como 
nós pensamos, o que a gente experimenta e o que nós fazemos todos os dias é muito uma matéria de metáfora.

Porém o nosso sistema conceitual não é algo ao qual habitualmente estejamos atentos. Nas menores coisas que fazemos todos os dias, nós simplesmente pensamos e agimos mais ou menos automaticamente ao longo de algumas diretrizes. O que essas diretrizes significam exatamente não é óbvio. Uma maneira de descobrir é olhando a linguagem. $\mathrm{Na}$ medida em que a comunicação é baseada no mesmo sistema conceitual que a gente usa para pensar e agir, a linguagem é uma importante fonte de evidência para o que é o sistema. (LAKOFF; JOHNSON, 1980, p. 3) (tradução livre) ${ }^{2}$

As palavras de Lakoff e Johnson (1980) conseguem, a nosso ver, ilustrar de maneira adequada a dificuldade relatada pelos informantes desta pesquisa. Seguindo seus preceitos para olhar a linguagem a fim de depreender o sistema conceitual metafórico que nos 'governa', fomos observar as manifestações discursivas que, mesmo com dificuldades, os que responderam ao questionário não se furtaram a produzir, e verificar de que modo os pesquisadores representam conceitualmente seu campo de pesquisa.

$\mathrm{Na}$ tentativa de estabelecer as bases sintáticas do elo semântico do enunciado e depreender as metáforas, optamos por trabalhar com as sentenças em que o verbo ser é explicitado ou não deixa margem à dúvida quanto à possibilidade de sua presença, ou ainda por verbo que indica a relação de semelhança, como, por exemplo, representar. Optamos por frases desse tipo - Transportes é... ou Transportes representa ... - , porque esses

\footnotetext{
2"The concepts that govern our thought are not just matters of the intellect. They also govern our everyday functioning, down to the most mundane details. Our concepts structure what we perceive, how we get around in the world, and how we relate to other people. Our conceptual system thus plays a central role in defining our everyday realities. If we are right in suggesting that our conceptual system is largely metaphorical, then the way we think, what we experience, and what we do every day is very much a matter of metaphor. But our conceptual system is not something we are normally aware of. In most of the little things we do every day, we simply think and act more or less automatically along certain lines. Just what these lines are is by no means obvious. One way to find out is by looking at language. Since communication is based on the same conceptual system that we use in thinking and acting, language is an important source of evidence for what that system is like".
}

Inf. Inf., Londrina, v. 22, n. 2, p. 99 - 116, maio/ago., 2017. 
verbos designam tanto a essência daquilo que é representado, quanto estado em que ele se apresenta.

Essa compreensão nos levou a considerar as cinco categorias fundamentais propostas por Ranganathan (1967) - personalidade, matéria, energia, espaço e tempo - para, com base nos enunciados formulados nas respostas ao questionário, identificar as metáforas que melhor identificariam essas respectivas facetas.

Assim, considerando o que nos diz Ranganathan (1967), percebemos que as categorias Tempo e Espaço seriam as de mais fácil identificação, haja vista sua concordância com o que comumente se entende por tempo e espaço, ou seja, a primeira se refere ao tratamento cronológico dos assuntos e a segunda, aos geográficos.

A categoria Energia apresenta um escopo maior de dificuldade, porque se reflete nas atividades que são próprias ao humano, ou seja, se manifesta nas atividades espirituais, mentais e físicas, traduzindo-se em inanimado, animado, conceitual, intelectual e intuitivo.

A categoria Matéria refere-se àquilo sobre o que o homem trabalha para conseguir um produto final; e a última categoria, Personalidade, considerada pelo próprio autor como a de maior grau de dificuldade de identificação, já que seria feita por exclusão. Isso significa dizer que uma dada manifestação se não é tempo, espaço, energia ou matéria, então é uma manifestação da categoria fundamental personalidade. Assim, esta última sintetiza a essência da entidade em questão. Admitimos, então, que a metáfora ontológica da área de transporte seria aquela que sinalizaria sua essência, conforme as definições consolidadas no QUADRO 1. 


\section{Quadro 1 - Definições de Transportes}

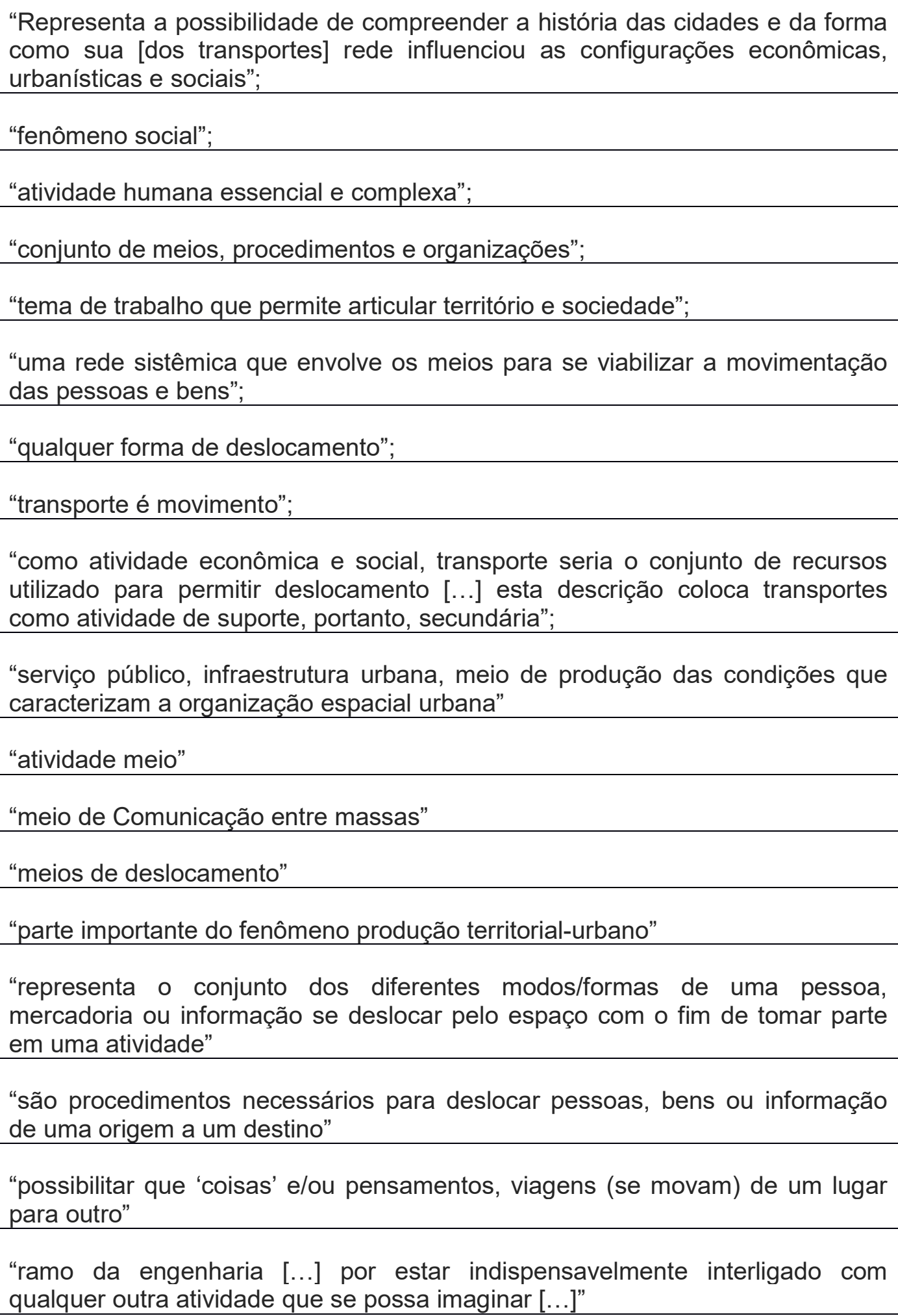

"ramo da engenharia [...] por estar indispensavelmente interligado com
qualquer outra atividade que se possa imaginar [...]" 
"A possibilidade de uma pessoa conhecer o mundo. Não é apenas viajar como turismo, mas interagir e poder melhor participar da sociedade. Hoje vejo como a possibilidade que as pessoas têm de ampliar seu espaço, suas relações, sua vida etc. A possibilidade de entrar em contato direto como outras pessoas e tudo o mais que daí pode decorrer."

Fonte: a autora.

A análise dos enunciados, recuperados dos questionários da Análise de Caso, enumerados no quadro 1 , revelou uma recorrente utilização de termos que se situam em três campos semânticos:

* rede / conjunto / sistema

* movimento / deslocamento / suporte

* meio / modo / procedimento

A análise dos dados indicou que as representações relativas ao campo semântico rede/conjunto/sistema se relacionavam à categoria Personalidade, na medida em que esta categoria sintetiza a essência da entidade em questão. A definição que melhor representa essa Personalidade é a que apresenta Transportes como rede sistêmica, porque transmite a noção de ser uma área que permite diversos "entes" - pessoas, mercadoria, ou informação entrarem em contato entre si ao se deslocarem de um ponto geográfico a outro. Ela traduz o conjunto de acontecimentos no espaço e no tempo, por meio de um sistema viário, colocando em relação pessoas e serviços tal qual uma rede.

A seguir, o segundo conjunto de termos vincula-se ao campo semântico movimento / deslocamento e suporte. Essas seriam a base de sustentação da rede sistêmica, pois representam sua "função". De alguma maneira, essa função está inerente e intrinsecamente associada às categorias de Espaço e Tempo. A primeira, Espaço, como exemplificado em "deslocar pessoas, bens ou informação de uma origem a um destino" não pode fugir à sua intrínseca relação com a categoria Tempo, já que tudo que se desloca no espaço o faz no decorrer de um espaço temporal.

Nesse grupo percebemos que os enunciados utilizados foram formulados, preferencialmente, por estruturas frasais que utilizam o verbo ser, 
mas com o significado - explicitado ou não - dos verbos viabilizar/permitir. Esse conjunto, então, foi relacionado à categoria Matéria, na medida em que essa categoria se refere àquilo sobre o que o homem trabalha para conseguir um produto final, ou seja, sua função: "Transporte é movimento". Podemos lançar mão de um exemplo no qual um pesquisador diz textualmente: "como atividade econômica e social, transporte seria o conjunto de recursos utilizado para permitir deslocamento...".

Como terceira categoria, apresentamos as representações metafóricas que relacionam a área de Transportes à categoria Energia. A definição de Ranganathan para essa faceta diz que energia se manifesta nas atividades espirituais, mentais e físicas, traduzindo-se em inanimado, animado, conceitual, intelectual e intuitivo, mas tomando o humano como referência. Como, na verdade, se está lidando com as representações que os humanos têm de seu campo de saber, resolvemos utilizar tal categoria, na medida em que o que nos interessa é a conceitualização que a comunidade discursiva faz sobre o fenômeno. Assim, no caso estudado, a metáfora utilizada é procedimento, na medida em que traduz a ação do transporte. Um exemplo ilustrativo é "Transportes são procedimentos necessários para deslocar pessoas, bens ou informação".

As facetas de Espaço e Tempo, no caso específico desse campo do conhecimento - Transportes -, são categorias inerentes à própria essência, porque estão intimamente ligadas ao conceito de deslocamento, e por isso é muito difícil para a comunidade conceitualizar sobre conceitos muito próximos às atividades usuais, conforme já dissemos.

Por fim, para completar o quadro das categorias propostas por Ranganathan, podemos pensar que os meios de deslocamento são a argamassa, ou a Matéria, pela qual a rede se viabiliza, ou seja, que a entidade executa suas funções de atividades/meios de deslocamento.

A partir desses dados, estabelecemos a proposta do metafiltro, cuja composição se faz por dois grupos de categorias: fundamentais e acessórias. Esclarece-se que são assim denominadas vis-à-vis o papel que podem exercer 
no campo da organização do conhecimento, na medida em que objetivamos recuperar informação. Para tal, procuramos identificar as categorias que servem para especificar (fundamentais) - ou não (acessórias) - a área de conhecimento em pauta e, em consequência, as metáforas a elas relacionadas.

As categorias fundamentais são aquelas que possuem caráter distintivo e portanto servem para tornar a informação mais específica, permitindo uma recuperação mais eficaz.

No caso da área estudada, temos como condições fundamentais as seguintes categorias: Essência, Função e Modo. Essas categorias correlacionam-se às facetas Personalidade, Matéria e Energia, representadas, respectivamente pelas metáforas atribuídas a transportes como rede sistêmica, movimento e procedimento, respectivamente.

As condições acessórias, pelas causas expostas, são representadas pelas facetas Espaço e Tempo e preenchem as categorias genéricas, não distintivas, denominadas de periféricas, sem representação metafórica, conforme ilustrado no fluxograma abaixo:

Figura 1. Fluxograma da relação entre condições fundamentais e condições acessórias

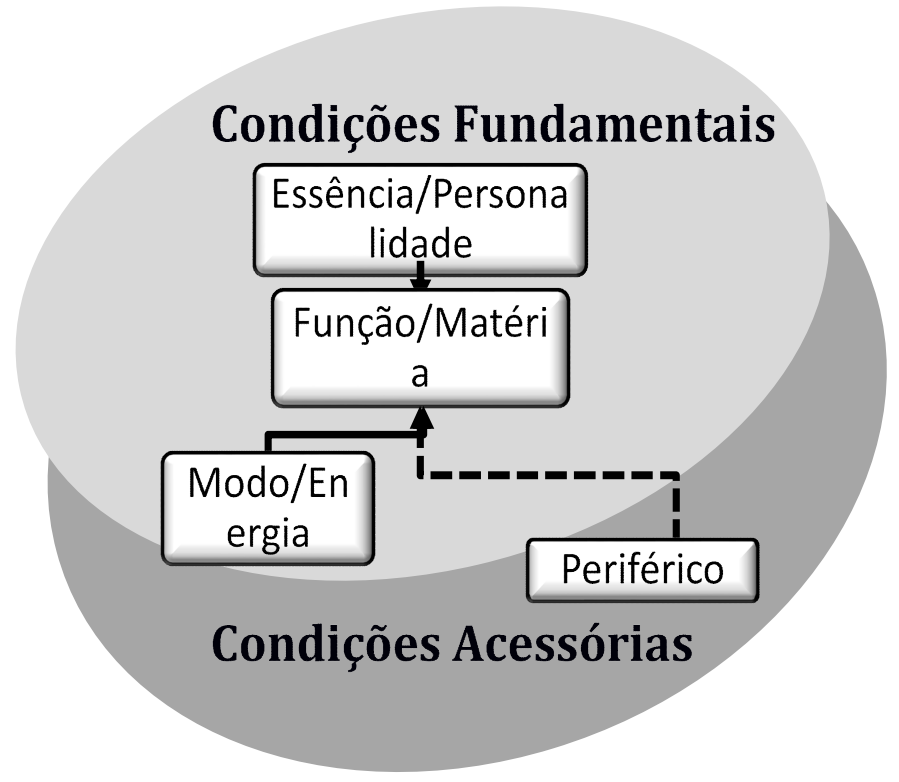

Fonte: elaborado pela autora

Inf. Inf., Londrina, v. 22, n. 2, p. 99 - 116, maio/ago., 2017. 
Pelos exemplos selecionados evidenciamos os termos utilizados pelos pesquisadores que conceituam a representação da área. Como esses termos repetiram-se por diferentes pesquisadores, e sendo essa equipe constituída por membros de diversos estados brasileiros e com diversificados níveis de experiência acadêmica, acreditamos ter conseguido identificar um esquema metafórico representativo da área.

Figura 2. Fluxograma da relação entre condições fundamentais e condições acessórias pelo esquema metafórico.

\section{Condições Fundamentais}

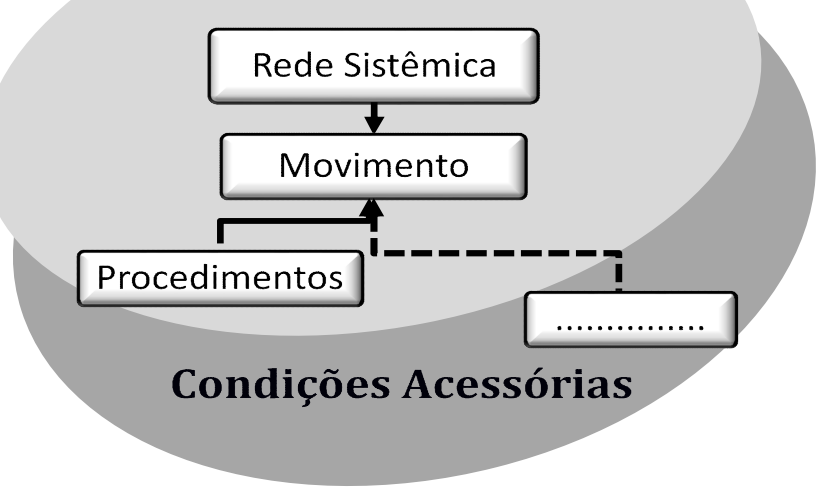

Fonte: elaborado pela autora.

A partir dos dados coletados nas entrevistas respondidas por e-mail, pudemos perceber que a metáfora que mais efetivamente define a essência do tema transportes, aquela que define a sua Personalidade, é a que relaciona transportes à rede sistêmica. Essa metáfora, pela força que exerce na construção das outras metáforas, é considerada a metáfora ontológica do tema.

A metáfora que relaciona transportes a movimento estabelece a função executada. Fazemos tal afirmação porque não existe transporte que não sirva para levar algo de um lugar a outro. É para fazer esse deslocamento que o transporte existe. 
A metáfora relativa a procedimento estabelece a relação do modo como esse transporte é realizado: seja por via terrestre, marítima, aérea, por ônibus, trem, barco ou avião, enfim, refere-se à maneira como algo é movimentado transportado - de um lugar a outro.

Por fim, consideramos como condições acessórias aquelas relacionadas a espaço e tempo. Parece contraditório, na medida em que não existe transporte que não seja a transmutação de algo a partir de um lugar em direção a outro e que isso ocorra necessariamente num intervalo de tempo. Justamente por isso, já que essas condições são inerentes ao tema transportes, não servem como distintivas do tema e, por essa razão, insuficientes para delimitar informação sobre ele.

\section{CONCLUSÃO}

As pessoas utilizam-se de metáforas como recurso de representação do mundo que os cerca e, assim, representam também metaforicamente as áreas de conhecimento em que atuam. Como as metáforas são estabelecidas entre os indivíduos que compõem um determinado grupo social e se reconhecem em virtude da identidade do grupo, acreditamos ter mostrado o uso de metáforas como recurso para aumentar a eficácia dos instrumentos de recuperação online em áreas de conhecimento específicas. Estudo de caso realizado com uma equipe de pesquisa na área de Transportes evidenciou um grupo de metáforas que, associado às concepções de faceta, pode servir de arcabouço teórico metaestrutural de filtro.

$\mathrm{Na}$ verdade, todo e qualquer critério de classificação, com seus subsequentes critérios de relevância, objetiva, em última instância, atender à expectativa de satisfação do usuário. Neste caso, nossa proposta de arcabouço teórico de filtro visa à utilização das metáforas que representam as categorias que satisfazem as condições fundamentais de representação da área de conhecimento. Essa organização classificatória objetiva aumentar a 
precisão na revocação de demandas na Internet, ou em qualquer outra base volumosa de dados.

As metáforas, nesse caso, estariam a serviço de uma busca por maior precisão, por mais paradoxal que isso possa parecer. Na verdade, pensamos a metáfora menos como recurso de estilo literário que tende à imprecisão, e mais como grau de representação que tende a especificar conceitos utilizados em um campo de conhecimento dado.

Em vista do exposto, acreditamos que essa proposta teórica de metafiltro possa servir de base para pesquisas futuras em outras áreas de conhecimento no intuito de identificar, em cada uma delas, o grupo de condições fundamentais e acessórias, bem como as metáforas empregadas para cada uma delas. Desse modo, acreditamos que ao serem identificadas as metáforas atribuídas às condições fundamentais, estas lhes sirvam de indicadores de especificidade e assim viabilizem maior precisão na recuperação de informação.

\section{REFERÊNCIAS}

HARTEL, Jenna; SAVOLAINEN, Reijo. Pictorial metaphors for information. Journal of Documentation. Vol. 72, no. 5, 2016. Pp.794.812 DOI 10.1108/JD07-2015-0080.

LAKOFF, George e JOHNSON, Mark. Metaphors we live by. Chicago: The University of Chicago Press, 1980.

ORRICO, Evelyn Goyannes Dill. Binômio Linguística-Ciência da Informação: abordagem teórica para elaboração de metafiltro de recuperação da informação. IBICT-UFRJ. Tese de Doutorado. Programa de Pós-Graduação em Ciência da Informação, CNPq-IBICT/DEP-UFRJ/ECO, 2001.

PRICE, Dereck J. de Solla. Little science, big science. New York: Columbia University Press, 1965.

RANGANATHAN, Shiyali Ramamrita. Prolegomena to library classification, Bombay: Asia Publishing House, 1967 


\title{
Title
}

Metaphors and knowledge organization: how do they communicate?

\begin{abstract}
Introduction; Since Johnson and Lakoff's (1980) postulation that cognitive organization takes place via metaphors, researchers have been trying to understand how such organization could represent knowledge. Objective: To build a theoretical model of an information retrieval filter - which we call meta-filter. Methodology: The discursive productions of a research group combining beginner and experienced researchers were analyzed. The goal was to identify the metaphors they used to represent their research object and their knowledge field.

Results: The analysis revealed the field's ontological metaphor, that is, the one that guides all representations in the field, as Transport is a systemic network. Conclusions: To know the field's ontological metaphor, and the subsequent other ones, when associated to Ranganathan's (1967) classification canons, allowed us to build a theoretical model of an information retrieval filter that could provide greater information retrieval precision in huge databases such as the internet.
\end{abstract}

Keywords: Metaphor. Knowledge Organization. Information Retrieval. Meta-filter.

Título

La metáfora y la organización del conocimiento: ¿cómo dialogan?

Resumen

Introducción: A partir de la presuposición de Johnson y Lakoff (1980) de que la organización cognitiva ocurre por vía metafórica, se ha buscado comprender cómo esa organización representaría el conocimiento. Objetivo: Proponer la construcción de un modelo teórico de filtro de recuperación de la información, al cual denominamos metafiltro. Metodología: Se analizaron las producciones discursivas de un grupo de investigación que congrega investigadores principiantes y experimentados, con el objetivo de deprender las metáforas utilizadas para representar su objeto de investigación y su campo de conocimiento. Resultados: Con este análisis se identificó la metáfora ontológica del área, es decir, la que nortea todas las representaciones del campo, a saber: Transporte es una red sistémica. Conclusiones: La identificación de la metáfora ontológica y de las demás metáforas de un campo del conocimiento, y se asocian a las facetas propuestas por Ranganathan (1967), nos permite ser posible alcanzar una mayor precisión en la recuperación de informaciones almacenadas en un enorme banco de datos como la internet.

Palabras clave: Metáfora. Organización del Conocimiento; Recuperación de la Información. Metafiltro.

Recebido: 10.03 .2017

Aceito: 25.08 .2017

Inf. Inf., Londrina, v. 22, n. 2, p. 99 - 116, maio/ago., 2017.

http:www.uel.br/revistas/informacao/ 